\title{
To study maternal mortality and complications leading to maternal death in the tertiary care centre
}

\author{
$\operatorname{Garg} \mathbf{P}^{1}$, \\ ${ }^{1}$ Dr. Pratibha Garg, Assistant Professor, Department of Obstetrics and Gynecology, Gajra Raja Medical College, MP, \\ India.
}

Address for Correspondence: Dr. Pratibha Garg, Email: drgargpratibha@gmail.com

\begin{abstract}
Objective: To study maternal mortality and complications leading to maternal death in the tertiary care centre over the five years of period. Method: A retrospective and prospective study of all maternal deaths from January 2001 to December 2005 was carried out. Results: There were total 204 maternal deaths out of 24,620 live births giving a maternal mortality rate (MMR) of 828.59 per 100,000 live births. Unbooked cases accounted for $74 \%$ of maternal deaths. The majority of deaths occurred in 25-29 years age group and 71\% were multigravida. Out of 204 maternal deaths $72.06 \%$ deaths were due to direct causes. Hemorrhage was the commonest cause of death (36\%) followed by toxaemia of pregnancy (19\%) and sepsis accounted for 135 of deaths. Conclusion: Hemorrhage, toxaemia of pregnancy and sepsis were found to be direct major cause of death. Anaemia and other indirect causes like jaundice, malaria, heart disease were other indirect causes of deaths.
\end{abstract}

Keywords: Maternal mortality, Rupture uterus, Postpartum Haemorrhage, Sepsis, Eclampsia, Anaemia.

\section{Introduction}

Maternal mortality is defined as per WHO (ICD-10) as death of a woman while pregnant or within 42 days of termination of pregnancy from any cause related to or aggregated by the pregnancy or its management but not from accidental or incidental cause. Late maternal death is defined as death of a woman from direct or indirect causes more than 42 days but less than one year after termination of pregnancy. Pregnancy related death is defined as death of a woman while pregnant or within 42 days of termination of pregnancy irrespective of the cause of death. Maternal death audits form the mainstay of evaluation of maternal health services in developing countries. Every minute, one woman dies due to pregnancy or child-birth related causes, this translates

Manuscript received: $01^{\text {st }} \mathrm{Feb} 2016$

Reviewed: $12^{\text {th }}$ Feb 2016

Author Corrected: $22^{\text {nd }}$ Feb 2016

Accepted for Publication: $01^{\text {st }}$ March 2016 into 1,500 women dying every day. According to statistics released by UNICEF and WHO 2006 in India every five minutes a woman dies during child birth [1]. In India the level of MMR has declined from 7501 in 1960 s to about 400 in 1990 s [2,3]. It is roughly estimated to be about 300 in 2003, though it is above 400 in some states [4,5]. Upto $80 \%$ of all maternal deaths are directly due to five complications, haemorrhage, sepsis, pregnancy-induced hypertension, rupture uterus and complication of abortions. A major cause for so many deaths due to hemorrhage is because, once bleeding starts, death can occur in around 2 hours compared within 10 hour for eclampsia and 72 hours for obstructed labour [6]. The aim of study was to assess the MMR in tertiary centre and find out the causes leading to maternal death.

\section{Result}

In our study average MMR was 828.59/100,000 live births from 2001-2005. Highest MMR reported was 1041.2/100,000 live births in the year 2002 and lowest 568.94/100,000 live births in 2005.[Table-1] . 74\% deaths occurred among unbooked patients, $26 \%$ occurred among booked patients. [Table -2] 
Table No 1: Year Wise Distribution of Maternal Deaths \& MMR

\begin{tabular}{|l|l|l|l|l|}
\hline S.NO. & Year & No. of live births & No. of death & MMR \\
& & & & (1 Lakh LB) \\
\hline 1. & 2001 & 4438 & 40 & 901.31 \\
\hline 2. & 2002 & 5182 & 44 & 849.09 \\
\hline 3. & 2003 & 4514 & 47 & 1041.2 \\
\hline 4. & 2004 & 5213 & 43 & 824.86 \\
\hline 5. & 2005 & 5273 & 30 & 568.94 \\
\hline Total & & $\mathbf{2 4 6 2 0}$ & $\mathbf{2 0 4}$ & $\mathbf{8 2 8 . 5 9}$ \\
\hline
\end{tabular}

Table No 2: Maternal Deaths in Booked and Emergency Cases

\begin{tabular}{|l|l|l|l|l|l|l|l|l|}
\hline S.NO. & $\begin{array}{l}\text { Booked/ } \\
\text { Emergency } \\
\text { Admission }\end{array}$ & $\mathbf{2 0 0 1}$ & $\mathbf{2 0 0 2}$ & $\mathbf{2 0 0 3}$ & $\mathbf{2 0 0 4}$ & $\mathbf{2 0 0 5}$ & Total & Percentage \\
\hline 1. & Booked & 8 & 13 & 15 & 10 & 7 & 53 & 26 \\
\hline 2. & Unbooked & 32 & 31 & 32 & 33 & 23 & 151 & 74 \\
\hline Total & & $\mathbf{4 0}$ & $\mathbf{4 4}$ & $\mathbf{4 7}$ & $\mathbf{4 3}$ & $\mathbf{3 0}$ & $\mathbf{2 0 4}$ & $\mathbf{1 0 0}$ \\
\hline
\end{tabular}

Table No 3: Maternal Deaths in Relation to Age

\begin{tabular}{|l|l|l|l|l|l|l|l|l|}
\hline S.NO. & $\begin{array}{l}\text { Maternal age } \\
\text { in year }\end{array}$ & $\mathbf{2 0 0 1}$ & $\mathbf{2 0 0 2}$ & $\mathbf{2 0 0 3}$ & $\mathbf{2 0 0 4}$ & $\mathbf{2 0 0 5}$ & Total & Percentage \\
\hline 1. & $15-19$ & 3 & 1 & 4 & 1 & 4 & 13 & 6.37 \\
\hline 2. & $20-24$ & 16 & 12 & 11 & 18 & 7 & 64 & 31.37 \\
\hline 3. & $25-29$ & 11 & 16 & 22 & 15 & 14 & 78 & 38.24 \\
\hline 4. & $30-34$ & 6 & 7 & 7 & 3 & 2 & 25 & 12.25 \\
\hline 5. & $35-39$ & 4 & 7 & 3 & 5 & 3 & 22 & 10.78 \\
\hline 6. & $40-45$ & - & 1 & - & 1 & - & 2 & 0.49 \\
\hline Total & & $\mathbf{4 0}$ & $\mathbf{4 4}$ & $\mathbf{4 7}$ & $\mathbf{4 3}$ & $\mathbf{3 0}$ & $\mathbf{2 0 4}$ & $\mathbf{1 0 0}$ \\
\hline
\end{tabular}


Table No 4: Death in Relation to Gravida

\begin{tabular}{|l|l|l|l|l|l|l|l|l|}
\hline S. No. & Gravida & $\mathbf{2 0 0 1}$ & $\mathbf{2 0 0 2}$ & $\mathbf{2 0 0 3}$ & $\mathbf{2 0 0 4}$ & $\mathbf{2 0 0 5}$ & Total & Percentage \\
\hline 1. & I & 12 & 13 & 11 & 16 & 7 & 59 & $\mathbf{2 9}$ \\
\hline 2. & II & 7 & 10 & 12 & 7 & 8 & 44 & $\mathbf{2 2}$ \\
\hline 3. & III & 9 & 10 & 12 & 7 & 7 & 45 & $\mathbf{2 2}$ \\
\hline 4. & IV & 6 & 6 & 6 & 6 & 5 & 29 & $\mathbf{1 4}$ \\
\hline 5. & V \& above & 6 & 5 & 6 & 7 & 3 & 27 & $\mathbf{1 3}$ \\
\hline Total & & $\mathbf{4 0}$ & $\mathbf{4 4}$ & $\mathbf{4 7}$ & $\mathbf{4 3}$ & $\mathbf{3 0}$ & $\mathbf{2 0 4}$ & $\mathbf{1 0 0 . 0 0}$ \\
\hline
\end{tabular}

Table No 5: Causes of Maternal Death $(n=204)$

\begin{tabular}{|c|c|c|c|}
\hline S.No. & Causes & No. & Percentage \\
\hline \multicolumn{4}{|c|}{ A. Indirect Causes } \\
\hline \multicolumn{4}{|c|}{ I. Haemorrhage } \\
\hline 1. & Rupture uterus/obst. Labour & 23 & 11 \\
\hline 2. & Placenta praevia & 7 & 3 \\
\hline 3. & $\mathrm{PPH}$ & 23 & 11 \\
\hline 4. & Retained Placenta & 9 & 4 \\
\hline 5. & Incomplete Abortion & 7 & 3 \\
\hline 6. & Ectopic Pregnancy & 4 & 2 \\
\hline 7. & Vesicular Mole & 1 & 0 \\
\hline \multicolumn{2}{|l|}{ Total } & 74 & 36 \\
\hline \multicolumn{2}{|c|}{ II. Toxaemia of pregnancy } & 38 & 19 \\
\hline \multicolumn{2}{|l|}{ III. Sepsis } & 26 & 13 \\
\hline \multicolumn{4}{|c|}{ IV. Other direct causes } \\
\hline 1. & IUD & 4 & 2.0 \\
\hline 2. & Post LSCS & 3 & 1.5 \\
\hline 3. & Retroverted Gravid Uterus & 1 & 0.5 \\
\hline 4. & Amniotic fluid embolism & 1 & 0.5 \\
\hline \multicolumn{2}{|l|}{ Total } & 9 & 4 \\
\hline
\end{tabular}




\begin{tabular}{|c|c|c|c|}
\hline \multicolumn{2}{|l|}{ Grand Total } & 147 & 72.06 \\
\hline \multicolumn{4}{|c|}{ B. Indirect Causes } \\
\hline 1. & Anaemia & 38 & 18.6 \\
\hline 2. & Jaundice & 6 & 2.9 \\
\hline 3. & Malaria & 9 & 4.4 \\
\hline 4. & Heart Disease & 2 & 1.0 \\
\hline \multicolumn{2}{|l|}{ Total } & 55 & 26.96 \\
\hline \multicolumn{4}{|c|}{ C. Unrelated Causes } \\
\hline 1. & Gastro Enteritis & 1 & 0.5 \\
\hline 2. & ARDS & 1 & 0.5 \\
\hline \multicolumn{2}{|l|}{ Total } & 2 & 0.98 \\
\hline
\end{tabular}

Table No 6: Types of Toxaemia $(n=38)$

\begin{tabular}{|l|l|l|l|l|l|l|l|l|}
\hline S.NO. & Type & $\mathbf{2 0 0 1}$ & $\mathbf{2 0 0 2}$ & $\mathbf{2 0 0 3}$ & $\mathbf{2 0 0 4}$ & $\mathbf{2 0 0 5}$ & Total & \% \\
\hline 1. & Antepartum eclampsia & 4 & 3 & 2 & - & 3 & 12 & 32 \\
\hline 2. & Intra partum eclampsia & 3 & 3 & 1 & 3 & - & 10 & 26 \\
\hline 3. & Post partum eclampsia & 2 & 3 & 3 & 1 & 1 & 10 & 26 \\
\hline 4. & Pre eclampsia & - & 1 & 3 & 2 & - & 6 & 16 \\
\hline & Total & 9 & 10 & 9 & 6 & 4 & 38 & 100 \\
\hline & Total Deaths & 40 & 44 & 47 & 43 & 30 & 204 & \\
\hline & Total Percentage & 23 & 23 & 19 & 14 & 13 & 19 & \\
\hline
\end{tabular}

Table No 7: Year Wise Distribution of Deaths Due to Anaemia

\begin{tabular}{|c|c|c|c|c|}
\hline S.No. & Year & Total Deaths & Death due to Anaemia & Percentage \\
\hline 1. & 2001 & 40 & 4 & 10 \\
\hline 2. & 2002 & 44 & 12 & 27 \\
\hline 3. & 2003 & 47 & 8 & 17 \\
\hline 4. & 2004 & 43 & 10 & 23 \\
\hline 5. & 2005 & 30 & 4 & 13 \\
\hline Total & & 204 & 19 & 18.6 \\
\hline
\end{tabular}


Majority of deaths occurred in 25-29 yrs age group, (38.24\%), $6.37 \%$ in teen age group and $0.49 \%$ in above 40 years age group. [Table-3] Majority of deaths occurred in primi (29\%) and 71\% in multi gravidae. [Table -4 ]. $90 \%$ of death occurred among rural patients and $10 \%$ among urban patients. 59\% of maternal deaths occurred among patients from low socioeconomic strata. Only $2 \%$ of maternal deaths occurred among patients form the affluent class. Majority of maternal deaths occurred in illiterate $(63 \%)$, as compared to educated $(37 \%)$. Only $9 \%$ of patients were referred cases. $72 \%$ of maternal deaths occurred in the post partum and puerperal period, $17 \%$ in antepartum period, $9 \%$ in postabortal and $2 \%$ in intrapartum period. History of interference by trained or untrained dai was present in $35 \%$ of maternal deaths. $51 \%$ of deaths occurred with in first 12 hours of admission, 22\% died within 24 hours. $7 \%$ of deaths occurred after 5 days of admission. $75 \%$ of the patients died after delivery of which $39.7 \%$ of babies were SB and $35.8 \%$ were alive. $13.2 \%$ cases died undelivered. Abortion related deaths were $8.8 \%$ and deaths due to ectopic pregnancy and vesicular mole were $2 \%$ and $0.5 \%$ respectively. Out of the 204 maternal deaths $147(72.06 \%)$ deaths were due to direct causes. In this group 36\% died due to haemorrhage, $19 \%$ due to toxaemia of pregnancy and sepsis accounted for $13 \%$ of deaths. One death $(0.5 \%)$ was due to obstructive uropathy complicating retroverted gravid uterus and one death was due to amniotic fluid embolism. Among 204 maternal deaths 55 cases (26.96\%) died due to indirect causes, of which maximum deaths $(18.6 \%)$ were due to anemia. Jaundice, malaria, heart disease accounted for $2.9 \%, 4.4 \%, 1 \%$ of deaths respectively. $0.98 \%$ of deaths were due to unrelated causes like gastro enteritis and ARDS. [Table- 5 ]. $11 \%$ of deaths were due to obstructed labour/ rupture uterus, deaths due to the same was maximum in $2002(14 \%) \& 2003(13 \%)$ and least in 2004 (2\%). $26 \%$ of deaths due to rupture uterus/obstructed labour occurred in III gravida. $60 \%$ of deaths due to obstructed labour/ rupture uterus occurred among patients with parity more than two. $48 \%$ of deaths were due to hypovolemic shock. CRA, pulmonary embolism, endotoxic shock and congestive cardiac failure accounted for 17\%, 13\%, 13\%, and $9 \%$ of deaths due to rupture uterus/obstructed labour respectively. 19\% deaths were due to APH and PPH. Of which $18 \%$ of deaths were due to placenta praevia, $44 \%$ were due to atonic $\mathrm{PPH}, 15 \%$ were due to traumatic $\mathrm{PPH}$, and $23 \%$ were due to retained placenta. $66 \%$ of deaths due to haemorrhage occurred in patients above parity two and $8 \%$ in primi. $66 \%$ of deaths were in the 20-30 years age group. 31-40 year age group accounted for 9\% of deaths due to APH and PPH. 74\% of deaths due to APH and PPH occurred within 12 hours of admission. out of the 39 deaths due to APH and PPH majority $(60 \%)$ died due to hypovolemic shock. CCF, CRA, Septic Shock, DIC, Pulmonary Embolism, Renal Failure accounted for $8 \%, 10 \%, 8 \% 3 \%, 8 \%, 3 \%$ of deaths respectively. $19 \%$ of deaths were due to eclampsia and preeclampsia. Of which $32 \%$ died due to antepartum eclampsia. Intrapartum eclampsia, post partum eclampsia and pre eclampsia accounted for $26 \%, 26 \%$ and $16 \%$ of deaths respectively [Table-6]. $50 \%$ of the deaths occurred among primi gravida and $5 \%$ of deaths occurred among grand multi. $26 \%$ of deaths were due to CCF. CRA, CVA, Pulmonary embolism, renal failure, endotoxic shock, hypovolemic shock accounted for $18 \%, 11 \%, 16 \%, 5 \%, 3 \%, 11 \%$ of deaths respectively among cases of eclampsia and pre eclampsia. 26 cases (13\%) deaths were due to sepsis. Of which puerperal sepsis and post abortal sepsis accounted for $58 \%$ and $42 \%$ respectively. $18.6 \%$ of deaths were due to anaemia. Maximum deaths (27\%) due to anaemia occurred in the year 2002 and least (13\%) in the year 2001.[Table-7] 29\% of deaths due to anemia occurred among primi, rest $71 \%$ deaths occurred among multigravidae with maximum (32\%) deaths among second gravidae. $63 \%$ of anaemia patients died due to CCF. CRA, Pulmonary embolism, Septic shock Haemorrhagic Shock and DVT accounted for $13 \%, 16 \%, 3 \%, 3 \%$ and $3 \%$ respectively.

\section{Discussion}

The MMR is our present study is 828.59 per 100,000 live births from 2001-2005 ranging from 1041.2 in year 2002 and lowest 568.94 in 2005. Most women were in poor general condition at the time of admission. $50 \%$ of deaths occurred within first 12 hours of admission. Various studies done in India in the last 15 years have shown wide variation in MMR ranging from 47/100000 to $625 / 100000$ births [7-12]. Madhu Jain has reported a very high MMR of 2270/100000 [8]. The higher incidence of deaths is due to non referral of cases from periphery. Most deaths were observed in the 25-29 yrs age group in present study whereas deaths were in 20 -
29 year age group in other studies [13]. Majority of deaths occurred in multigravida, majority of deaths were due to direct causes $(72.06 \%)$ comparable with study done by Bhaskar k Murthy et al [13] Hemorrhage and sepsis were the major direct killers and were comparable to other studies [13]. In our study, 19\% deaths were due to APH and $\mathrm{PPH}$ and $19 \%$ were due to eclampsia and preeclampsia. The use of magnesium sulfate and early termination with medication had lead to improve the scenario of eclampsia. Indirect causes of death in our study accounted for $26.96 \%$. Out of which anaemia (18.6\%) had contribute the majority. Anaemia 
is probably a chronic rather than acute condition in many cases. There is a resulting compensatory shift of the oxygen dissociation curve to the right. Thus, women with very low haemoglobin concentrations may be seen in the antenatal period without the expected overt symptoms of cardiac failure. They will, however, easily become tired by any form of physical activity and may decompensate, e.g. as a result of labour. Should any adverse event such as bleeding occur, their risk of death is high [14].

\section{Conclusion}

The most of maternal death are preventable. Sustained reductions in maternal mortality will only be possible if madam high-quality obstetric care in made available to all women through a system of professional midwifery and referral hospital care in the context of political commitment and accountability of health providers. The availability of blood bank at all first referral units (FRUs) and their proper functioning are needed. The provision of timely blood transfusion can save many lives. Health education of masses alongwith good quality health care and transport facilities can prevent many deaths.

\section{Funding: Nil}

Conflict of interest: None.

Permission of IRB: Yes

\section{References}

1. UNICEF \& WHO 2006 in India http://www.org.uk/press/news-details-full-strong.asp? news id $=626$

2. Bhat PN, Navaneetham K, Rajan SI. Maternal mortality in India: estimates from a regression model. Stud Fam Plann. 1995 Jul-Aug;26(4):217-32.

3. Bhat PN. Maternal mortality in India: an update. Stud Fam Plann. 2002 Sep;33(3):227-36.

4. Registrar General of India. maternal mortality in India 1997-2003. Trends, causes and risk factors. Report 2006, Registrar General India: New Delhi, p. 129.
5. Singh P, Pandey A, Aggarwal A. House to house survey vs. snowballing survey technique for capturing maternal deaths in India: A pilot study in search of cost effective method. Indian $\mathrm{J}$ med Res $125[2007] 60$

6. ACOG Committee Opinion. American College of Obstetrician and Gynecologist. ACOG Committee Opinion. Number 283, May 2003. New U.S. Food and Drug Administration labeling on Cytotec (misoprostol) use and pregnancy. Obstet Gynecol. 2003 May;101(5 Pt 1):1049-50.

7. Puri A, Yadav I, Jain N. Maternal mortality in an urban Tertiary care hospital of north India. J Obstet Gynaecol India. 2011;61:280-5.

8. Jain M, Maharahaje S. Maternal mortality: A retrospective analysis of ten years in a tertiary hospital.Indian J Prev Soc Med. 2003;34:103-11.

9. Jadhav AJ, Rote PG. Maternal mortality-changing trends. J Obstet Gynaecol India. 2007;57:398-400.

10. Pal A, Ray P, Hazra S, Mondal TK. Review of changing trends in maternal mortality in a rural medical college in west Bengal. J Obstet Gynecol India. 2005;55:521-4.

11. Onakewhor JU, Gharoro EP. Changing trends in maternal mortality in a developing country. Niger J Clin Pract. 2008 Jun;11(2):111-20.

12. Shah RJ, Ali I, Banday A, Fazili A, Khan I. Analysis of maternal mortality in a small teaching hospital attached to tertiary care hospital. Indian J Community Med. 2008;33:260-2.

13. Murthy BK, Murthy MB, Prabhu PM. Maternal Mortality in a Tertiary Care Hospital: A 10-year Review. Int J Prev Med. 2013 Jan;4(1):105-9.

14. van den Broek N. Anaemia and micronutrient deficiencies. Br Med Bull. 2003;67:149-60.

\section{How to cite this article?}

Garg P, To study maternal mortality and complications leading to maternal death in the tertiary care centre. Int $J$ Med Res Rev 2016;4(3):347-352. doi: 10.17511/ijmrr.2016.i03.10 